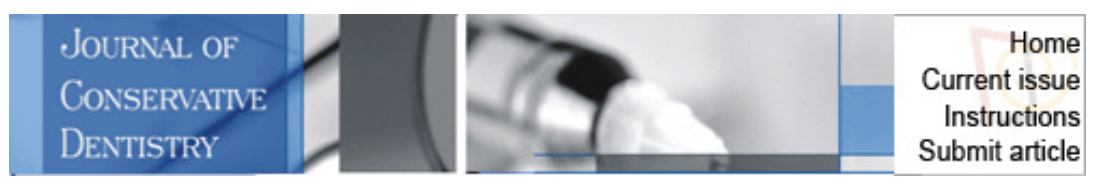

J Conserv Dent. 2016 Sep-Oct; 19(5): 478-481. doi: $\underline{10.4103 / 0972-0707.190008}$

\title{
Centering and transportation: in vitro evaluation of continuous and reciprocating systems in curved root canals
}

Beatriz Vilas Navós, Carolina Bender Hoppe, ${ }^{1}$ Leticia Boldrin Mestieri, ${ }^{1}$ Daiana Elizabeth Böttcher, ${ }^{1}$ Marcus Vinicius Reis Só, ${ }^{1}$ and Fabiana Soares Grecca ${ }^{1}$

Department of Endodontics, School of Dentistry, University of Republic, Montevideo, Uruguay

${ }^{1}$ Department of Conservative Dentistry, School of Dentistry, Federal University of Rio Grande do Sul, Porto Alegre, RS, Brazil

Address for correspondence: Dr. Fabiana Soares Grecca, Department of Conservative Dentistry, School of Dentistry, Federal University of Rio Grande do Sul, Av. Ramiro Barcelos, 2492 - Porto Alegre, RS 90035-003, Brazil. E-mail: fabiana.grecca@ufrgs.br

Received 2016 May 23; Revised 2016 Jul 13; Accepted 2016 Aug 18.

Copyright : @ Journal of Conservative Dentistry

This is an open access article distributed under the terms of the Creative Commons Attribution-NonCommercial-ShareAlike 3.0 License, which allows others to remix, tweak, and build upon the work non-commercially, as long as the author is credited and the new creations are licensed under the identical terms.

\section{Abstract}

\section{Context:}

One of the goals of endodontic therapy is the shaping and cleaning of the root canal system. In recent years, there has been multiple systems instrumentation, and changes in their dynamics are central to maintain the original shape of the canal after preparation.

Aims:

The aim of this study was to evaluate centering and transportation in curved root canals after using ProTaper ${ }^{\circledR}$ and MTwo $^{\circledR}$ in continuous rotation, Reciproc ${ }^{\circledR}$ in reciprocating motion, and a step-down manual instrumentation technique.

\section{Settings and Design:}

Mesiobuccal roots of human extracted the first and second maxillary molars were selected and the canals $(n=60)$ were divided into four groups according to the preparation techniques: PT-ProTaper ${ }^{\circledR}$; MT-MTwo ${ }^{\circledR}$; RE-Reciproc ${ }^{\circledR}$; MI-manual instrumentation.

\section{Subjects and Methods:}

The final apical diameter was standardized to a size 25. Centering and transportation were evaluated by cone-beam computed tomography and Adobe Photoshop 8.0 software.

\section{Statistical Analysis Used:}

The data were statistically analyzed by ANOVA and Tukey post hoc.

Results:

Results of transportation showed no statistical differences $(P>0.05)$ between groups, and significantly, difference $(P<$ 0.05 ) between ProTaper ${ }^{\circledR}$ and Reciproc ${ }^{\circledR}$ was found when evaluating centering ability in the apical third.

\section{Conclusions:}

We concluded that there were no differences in transportation between the evaluated systems for the preparation of curved root canals with an apical instrumentation diameter of \#25. For centering ability, in the apical third, ProTaper ${ }^{\circledR}$ presented worst behavior when compared to Reciproc ${ }^{\circledR}$.

Keywords: Cone-beam computed tomography, endodontics, nickel-titanium alloy, root canal preparation

\section{INTRODUCTION}

One of the purposes of endodontic therapy is to achieve cleaning and shaping of root canal system. The preparation of the 
anatomical canal, giving it a cylindrical-conical shape, should respect the original features while also maintaining the integrity of the apical foramen.[1]

Shaping of curved canals has been offset by a tendency for all preparation techniques to deviate the prepared canal from its original axis.[2] Thus, several thermomechanical processes and manufacturing technologies were developed to improve the microstructure of nickel-titanium alloys, making them more flexible, [3] resistant[4] and with an increased cutting power.[2]

Centering ability is influenced by the design of the instrument (taper, flexibility, and type of alloy) and the root canal anatomy.[5] With the aim of simplifying the preparation procedures and decreasing the canal transportation, a single instrument associated to reciprocal motion was proposed.[6, 7 ] This movement was developed to relieve torsional and flexural stress, to improve centralization, and to reduce the risk of canal deformation during preparation.[]

The aim of this study was to evaluate centering ability and transportation in curved root canals after using ProTaper ${ }^{\circledR}$ and MTwo ${ }^{\circledR}$ in continuous rotation, Reciproc ${ }^{\circledR}$ in reciprocating motion, and a step-down manual instrumentation technique by means of cone-beam computed tomography (CBCT) evaluation. The null hypothesis is that there is no difference among the evaluated systems regarding apical transportation and centering ability.

\section{SUBJECTS AND METHODS}

After approval from the Research Ethics Committee, sixty maxillary first and second molar teeth, obtained from a Teeth Bank by a written consent, with complete root formation and similar root shapes were selected for the study. Each tooth was sectioned through furcation and the mesiobuccal root was used. Periapical radiographs were taken to confirm complete root canal formation, canal curvature, absence of calcifications, resorptions, and previous root canal treatment.

\section{Sample}

Root canals were randomly divided into four groups $(n=15)$ according to the degree and radius of canal curvature.[ㄹ, 10$]$ Curvatures between $20^{\circ}$ and $40^{\circ}$ and radius $<10 \mathrm{~mm}$ comprised the sample. After endodontic access, the canals were irrigated with $2.5 \%$ sodium hypochlorite solution ( $\mathrm{NaOCl}$; Farmácia Marcela, Porto Alegre, RS, Brazil) using a plastic syringe with a NaviTip needle (NaviTip 31-gauge sideport; Ultradent, South Jordan, UT, USA) and explored with a \#10 Triple Flex file (SybronEndo, Glendora, CA, USA) fitted snugly in the apical foramen. Working length was determined by subtracting $1 \mathrm{~mm}$ from the total length. Apices were sealed with sticky wax and fixed in an acrylic block, except for the first $2 \mathrm{~mm}$ of the cervical third.. The roots were fixed to an acrylic board to maintain its position during the acquisition of the preoperative and postoperative images and root canal preparation.

\section{Root canal instrumentation}

One experienced operator carried out the canal preparation. In all groups, canals were irrigated with $2 \mathrm{~mL}$ of $2.5 \% \mathrm{NaOCl}$ before each instrument was inserted. Recapitulation was performed after each instrument with a \#10 Triple Flex file (SybronEndo, Glendora, CA, USA). Final irrigation was performed with $2 \mathrm{~mL}$ of $17 \%$ ethylenediaminetetraacetic acid (Farmácia Marcela, Porto Alegre, RS, Brazil) during $3 \mathrm{~min}$, followed by $2 \mathrm{~mL}$ of $2.5 \% \mathrm{NaOCl}$. Canals were then dried with sterilized paper points. Mechanical operation of the instruments was performed with a reducing contra-angle 6:1 Sirona (VDW GmbH, Munich, Germany) coupled to micro-motor SM 16845 (VDW GmbH, Munich, Germany) connected to an electric motor VDW Silver with VDW update Reciproc ${ }^{\circledR}$ (VDW GmbH, Munich, Germany).

The groups were nominated as follows: PT-ProTaper ${ }^{\circledR}$; MT-MTwo ${ }^{\circledR}$; RE-Reciproc ${ }^{\circledR}$; MI-manual instrumentation. ProTaper ${ }^{\circledR}$ instruments were used in a crown-down manner and continuous rotary motion. Preparation of coronal and middle thirds was carried out by S1 and SX files. Then, S1 file was used to the working length followed by S2. Instrumentation was completed with the F1 and F2 instruments, in this order, to obtain a final apical size \#25. Brushing movements were used for S files and in-and-out motion for F files. For Mtwo ${ }^{\circledR}$, the sequence used was 10.04, 15.05, 20.06, and 25.06 at the working length using a careful in-and-out motion with continuous rotary. Reciproc ${ }^{\circledR}$ file (size 25.08) was used in a reciprocating, slow in-and-out pecking motion according to the manufacturer's instructions. Preparation was divided into three stages (coronal, middle, and apical thirds) and the instrument was cleaned after three pecks. For manual instrumentation, the canal was instrumented using crown-down technique, and the canals were prepared until the working length of a \#25 K-file (SybronEndo, Glendora, CA, USA). Except for Reciproc ${ }^{\circledR}$, at each instrument change, irrigation and recapitulation with a \#10 Triple Flex (SybronEndo, Glendora, CA, USA) file at the length of work were performed. Each instrument was used to prepare three root canals and then discarded. If, during use, instrument fracture happened, it was replaced. Information related to the instrument type and number of users was noted on a worksheet.

\section{Cone-beam computed tomography evaluation}

CBCT images were obtained before and after instrumentation. At the end of instrumentation, the prepared roots were 
replaced in the acrylic device, in the same exact position, to perform a new scan using the same parameters. The scanner i-CAT (Imaging Sciences International, Hatfield, PA, USA) was used according to the automatic image capture parameters of the i-CAT Vision System (Imaging Sciences International, Hatfield, PA, USA) software. This device has a radiation source of high frequency, $120 \mathrm{kVp}, 3-8 \mathrm{~mA}, 14 \mathrm{bit}$ - grayscale, and voxel size of $0.4 \mathrm{~mm}$. The snapshot was performed in a single rotation of $360^{\circ}$ with scanning time of $20 \mathrm{~s}$. Two axial sections of each sample, one in the coronal third (at $9 \mathrm{~mm}$ from the apex) and another in the apical third (at $3 \mathrm{~mm}$ from the apex), before and after preparation, were selected. The selected images were transferred to Adobe Photoshop 8.0 software (Adobe Systems, San Jose, CA, USA).

One operator, trained and calibrated, performed the measurements. To evaluate the transport and centering ability, the method described by Gambill et al.[11] and Stern et al.[12] was adopted. Transportation was calculated as follows: ( $\mathrm{X}_{1-}$ $\left.\mathrm{X}_{2}\right)-\left(\mathrm{Y}_{1}-\mathrm{Y}_{2}\right) . \mathrm{X}_{1}$ represents the shortest distance from the furcal (distal) aspect of the root to the periphery of the uninstrumented canal. $X_{2}$ represents the shortest distance from the furcal (distal) aspect of the root to the periphery of the prepared canal. $\mathrm{Y}_{1}$ represents the shortest distance from the mesial aspect of the root to the periphery of the uninstrumented canal. $\mathrm{Y}_{2}$ represents the shortest distance from the mesial aspect of the root to the periphery of the prepared canal. A result of zero indicated no canal transportation; a positive result indicated transportation toward the furcal (distal) aspect of the root; a negative result indicated transportation toward the mesial aspect of the root. Centering ability was calculated by the formula: $\left(\mathrm{X}_{1}-\mathrm{X}_{2}\right) /\left(\mathrm{Y}_{1}-\mathrm{Y}_{2}\right)$ or $\left(\mathrm{Y}_{1}-\mathrm{Y}_{2}\right) /\left(\mathrm{X}_{1}-\mathrm{X}_{2}\right)$.[11] A result of one would indicate perfect centering ability; the closer the result is to zero, the worse the ability is of the instrument to remain centered.

\section{Statistical analysis}

Data were presented by mean and standard deviation. Results were analyzed by ANOVA and Tukey post hoc tests by means of the software SPSS Statistics 19.0 (SPSS IBM Corporation, Armonk, NY, USA) with a significance level of 5\%.

\section{RESULTS}

All evaluated systems showed no difference for centering ability in the cervical portion $(P>0.05)$. Reciproc ${ }^{\circledR}$ presented a worse behavior, in the apical third $(P=0.032)$, when compared to ProTaper ${ }^{\circledR}$ [Table 1]. Regarding canal transportation, there were no significant statistical differences among the experimental groups in both apical and cervical thirds $(P>$ $0.05)$ [Table 2]. One \#10 MTwo ${ }^{\circledR}$ instrument fractured during its third use, and one \#25 Reciproc ${ }^{\circledR}$ instrument presented alterations at the end of the active portion after three uses. Considering the results, the null hypothesis is rejected.

\section{DISCUSSION}

During the preparation of root canals, there is the intention to maintain its original shape and position. Trajectory deviation can be caused by instrumentation, leading to difficulties in obtaining the correct cleaning and subsequent filling, threatening the success of endodontic treatment.[13] Historically, studies evaluating the instrumentation of root canals have been conducted by means of radiographic analysis, serial sections, diafanization, clinical and scanning electron microscopy. $[14,15,16,17,18]$ Nevertheless, none of these methods are able to analyze the specimen without altering it, beyond the impossibility to evaluate it in three dimensions.[19] Computed tomography is a noninvasive technique that allows assessment of structures and is frequently used to evaluate the canal morphology before and after instrumentation,[20] being considered the gold standard in studies ex-live.[21]

Nazari Moghadam et al.[5] emphasizes that apical transportations that are $>0.3 \mathrm{~mm}$ can jeopardize the outcome of treatment due to the significant decrease in the sealing ability of root filling material; thus, studies that evaluate apical deviation are important tools to improve clinical practice. The centralization of instruments in root canals is also an important factor to be considered for the evaluation of possible deviations arising from the instrumentation.[22] Results showed that the kinematics of movements and the file sequences influenced the centering ability. In the apical third, the single-instrument system, Reciproc ${ }^{\circledR}$, showed the different behavior when compared to ProTaper ${ }^{\circledR}$ but did not differ from manual and MTwo ${ }^{\circledR}$ groups. Maitin et al.[4] also observed different behavior for ProTaper ${ }^{\circledR}$ when compared to MTwo ${ }^{\circledR}$. Furthermore, it must be considered that cervical preparation can influence the outcome. In addition, the thermomechanical treatment developed to modify the NiTi alloy in reciprocating instruments to increase the flexibility may not have improved their performance.[2]

Peters[23] defined transportation as any undesirable deviation from the natural path of the canal. Several authors show that rotary systems promote less canal transportation than manual instrumentation.[24,25] In our study, the values obtained for transport in the apical third were very close to zero, indicating no canal transportation for all groups. This result is probably due to the small apical diameter used during canals preparation (\#25) as they are narrow and curved. Regarding canal transportation in the coronal root third, even with no statistically significant difference, ProTaper ${ }^{\circledR}$ showed transportation toward the furcal aspect, also reported in previous studies.[4] This might be attributed to the brushing motion during rotary instrumentation.

Stern et al. $[\underline{12}]$ evaluated the centering and the shaping ability of ProTaper ${ }^{\circledR}$ used in reciprocating motion and in 
continuous rotary motion observing no differences between the techniques, corroborating with our results. These results were also described by Nazari Moghadam et al.,[5] when comparing Reciproc ${ }^{\circledR}$ with a rotary motion system (Twisted File ${ }^{\circledR}$ ). In this study, there was a separation of one \#10 MTwo ${ }^{\circledR}$ instrument in its third use and one \#25 Reciproc ${ }^{\circledR}$ instrument showed alterations at the end of the active portion after three uses. These changes may be related to the absence of cervical preflaring in these experimental groups.

In the search for new instruments and systems that contribute for the simplification of endodontic procedures, it is a risk to consider valid only the arguments used by manufacturers, which can confuse simplification with simplicity.

Technological development has contributed to the improvement of technical procedures, and there is a faint line between clinical significance and research findings published.

\section{CONCLUSION}

From the results of this study, it can be concluded that there was no difference in transportation between systems of continuous rotation (ProTaper ${ }^{\circledR}$ and MTwo ${ }^{\circledR}$ ), reciprocating motion (Reciproc ${ }^{\circledR}$ ), and manual crown-down instrumentation for the preparation of curved root canals when using the apical instrumentation diameter \#25.

\section{Financial support and sponsorship}

Nil.

\section{Conflicts of interest}

There are no conflicts of interest.

\section{REFERENCES}

1. Degerness RA, Bowles WR. Dimension, anatomy and morphology of the mesiobuccal root canal system in maxillary molars. J Endod. 2010;36:985-9. [PubMed: 20478451]

2. Maitin N, Arunagiri D, Brave D, Maitin SN, Kaushik S, Roy S. An ex vivo comparative analysis on shaping ability of four NiTi rotary endodontic instruments using spiral computed tomography. J Conserv Dent. 2013;16:219-23.

[PMCID: PMC3698584] [PubMed: 23833454]

3. Shen Y, Zhou HM, Zheng YF, Peng B, Haapasalo M. Current challenges and concepts of the thermomechanical treatment of nickel-titanium instruments. J Endod. 2013;39:163-72. [PubMed: 23321225]

4. Kim HC, Kwak SW, Cheung GS, Ko DH, Chung SM, Lee W. Cyclic fatigue and torsional resistance of two new nickel-titanium instruments used in reciprocation motion: Reciproc versus WaveOne. J Endod. 2012;38:541-4. [PubMed: 22414846]

5. Nazari Moghadam K, Shahab S, Rostami G. Canal transportation and centering ability of twisted file and Reciproc: a cone-beam computed tomography assessment. Iran Endod J. 2014;9:174-9. [PMCID: PMC4099947] [PubMed: 25031589]

6. Berutti E, Paolino DS, Chiandussi G, Alovisi M, Cantatore G, Castellucci A, et al. Root canal anatomy preservation of WaveOne reciprocating files with or without glide path. J Endod. 2012;38:101-4. [PubMed: 22152630]

7. Yared G. Canal preparation using only one Ni-Ti rotary instrument: preliminary observations. Int Endod J. 2008;41:339-44. [PubMed: 18081803]

8. Plotino G, Grande NM, Testarelli L, Gambarini G. Cyclic fatigue of Reciproc and WaveOne reciprocating instruments. Int Endod J. 2012;45:614-8. [PubMed: 22268461]

9. Schäfer E, Diez C, Hoppe W, Tepel J. Roentgenographic investigation of frequency and degree of canal curvatures in human permanent teeth. J Endod. 2002;28:211-6. [PubMed: 12017184]

10. Schneider SW. A comparison of canal preparations in straight and curved root canals. Oral Surg Oral Med Oral Pathol. 1971;32:271-5. [PubMed: 5284110]

11. Gambill JM, Alder M, del Rio CE. Comparison of nickel-titanium and stainless steel hand-file instrumentation using computed tomography. J Endod. 1996;22:369-75. [PubMed: 8935064]

12. Stern S, Patel S, Foschi F, Sherriff M, Mannocci F. Changes in centring and shaping ability using three nickeltitanium instrumentation techniques analysed by micro-computed tomography ( $\mu \mathrm{CT}$ ) Int Endod J. 2012;45:514-23. [PubMed: 22625863]

13. Ounsi HF, Franciosi G, Paragliola R, Al-Hezaimi K, Salameh Z, Tay FR, et al. Comparison of two techniques for 
assessing the shaping efficacy of repeatedly used nickel-titanium rotary instruments. J Endod. 2011;37:847-50. [PubMed: 21787503]

14. Baldassari-Cruz LA, Lilly JP, Rivera EM. The influence of dental operating microscope in locating the mesiolingual canal orifice. Oral Surg Oral Med Oral Pathol Oral Radiol Endod. 2002;93:190-4. [PubMed: 11862210]

15. Kulild JC, Peters DD. Incidence and configuration of canal systems in the mesiobuccal root of maxillary first and second molars. J Endod. 1990;16:311-7. [PubMed: 2081944]

16. Omer OE, Al Shalabi RM, Jennings M, Glennon J, Claffey NM. A comparison between clearing and radiographic techniques in the study of the root-canal anatomy of maxillary first and second molars. Int Endod J. 2004;37:291-6. [PubMed: 15086749]

17. Paqué F, Balmer M, Attin T, Peters OA. Preparation of oval-shaped root canals in mandibular molars using nickeltitanium rotary instruments: a micro-computed tomography study. J Endod. 2010;36:703-7. [PubMed: 20307747]

18. Vertucci FJ. Root canal anatomy of the human permanent teeth. Oral Surg Oral Med Oral Pathol. 1984;58:589-99. [PubMed: 6595621]

19. Baratto Filho F, Zaitter S, Haragushiku GA, de Campos EA, Abuabara A, Correr GM. Analysis of the internal anatomy of maxillary first molars by using different methods. J Endod. 2009;35:337-42. [PubMed: 19249591]

20. Moore J, Fitz-Walter P, Parashos P. A micro-computed tomographic evaluation of apical root canal preparation using three instrumentation techniques. Int Endod J. 2009;42:1057-64. [PubMed: 19912375]

21. Blattner TC, George N, Lee CC, Kumar V, Yelton CD. Efficacy of cone-beam computed tomography as a modality to accurately identify the presence of second mesiobuccal canals in maxillary first and second molars: a pilot study. J Endod. 2010;36:867-70. [PubMed: 20416435]

22. Aguiar CM, Sobrinho PB, Teles F, Câmara AC, de Figueiredo JA. Comparison of the centring ability of the ProTaper $^{\mathrm{TM}}$ and ProTaper Universal ${ }^{\mathrm{TM}}$ rotary systems for preparing curved root canals. Aust Endod J. 2013;39:25-30. [PubMed: 23551510]

23. Peters OA. Current challenges and concepts in the preparation of root canal systems: a review. J Endod. 2004;30:559-67. [PubMed: 15273636]

24. Hülsmann M, Peters OA, Dummer PM. Endodontic Topics. Oxford: Blackwell Munksgaard; 2005. Mechanical preparation of root canals: Shaping goals, techniques and mean; pp. 30-76.

25. Versiani MA, Pascon EA, de Sousa CJ, Borges MA, Sousa-Neto MD. Influence of shaft design on the shaping ability of 3 nickel-titanium rotary systems by means of spiral computerized tomography. Oral Surg Oral Med Oral Pathol Oral Radiol Endod. 2008;105:807-13. [PubMed: 18424117] 
Table 1

\begin{tabular}{lcc}
\hline Group & Cervical & Apical \\
\hline PT & $0.58 \pm 0.30$ & $0.83 \pm 0.35^{\text {a }}$ \\
MT & $0.78 \pm 0.68$ & $0.56 \pm 0.30^{\text {sb }}$ \\
RE & $0.54 \pm 0.26$ & $0.49 \pm 0.37^{\text {b }}$ \\
MI & $0.54 \pm 0.24$ & $0.80 \pm 0.27^{\text {ab }}$ \\
\hline
\end{tabular}

In column: Mean values followed by different superscript letters are significantly different.

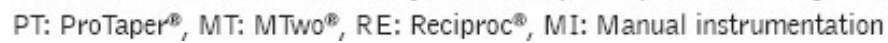

Means and standard deviations of centering ratio 


\section{Table 2}

\begin{tabular}{lcc}
\hline Group & Cervical & Apical \\
\hline PT & $0.19 \pm 0.78$ & $-0.06 \pm 0.27$ \\
MT & $-0.31 \pm 0.80$ & $0.0 \pm 0.11$ \\
RE & $-0.07 \pm 0.80$ & $0.07 \pm 0.25$ \\
MI & $-0.28 \pm 0.84$ & $-0.05 \pm 0.08$ \\
\hline
\end{tabular}

PT: ProTaper ${ }^{\infty}$, MT: MTw0 $0^{\infty}$ RE: Reciproc ${ }^{\infty}$, MI: Manual instrumentation

Means and standard deviations of canal transportation ( $\mathrm{mm})$

Articles from Journal of Conservative Dentistry : JCD are provided here courtesy of Wolters Kluwer -- Medknow Publications 